\title{
Synthesis and structural characterization of zirconium phosphate adipate dimethyl sulphoxide: A new lambda-type organic-inorganic layered material
}

\author{
HUSSEIN ALHENDAWI* \\ Department of Chemistry, Faculty of Science, Al-Azhar University of Gaza, 1277 Gaza, Palestine \\ e-mail: hussein.alhendawi@yahoo.com
}

MS received 13 December 2013; revised 15 February 2014; accepted 18 February 2014

\begin{abstract}
Zirconium phosphate adipate dimethyl sulphoxide, $\lambda-\mathrm{ZrPO}_{4}\left(\mathrm{OOC}-\left(\mathrm{CH}_{2}\right)_{4}-\mathrm{COOH}\right)\left(\mathrm{CH}_{3}\right)_{2} \mathrm{SO}$, is prepared by means of topotactic anion exchange of the chloride ligand of $\lambda$-Zirconium phosphate, $\lambda$ $\mathrm{ZrPO} \mathrm{Cl}_{4} \mathrm{Cl}\left(\mathrm{CH}_{3}\right)_{2} \mathrm{SO}$, with adipate. The samples are characterized by thermal analyses, X-ray diffractometry and FT-IR spectrophotometry. The used analysis approaches provide strong evidence that the chloride monovalent anions of $\lambda$-Zirconium phosphate are completely exchanged with the carboxylate groups of the adipate monoanionic ligands. Moreover, the adipate ligands replace the chloride anions in a 1:1 stoichiometry. In this case the formula of the derivative should contain the monoanionic adipate fragment: $\left(\mathrm{OOC}-\left(\mathrm{CH}_{2}\right)_{4}-\mathrm{COOH}\right)$. This formula is in agreement with TGA and elemental analysis. With respect to intercalation properties, the synthesized adipate-solid phase has a higher acidic character and a larger gallery height in comparison to the pristine $\lambda$-Zirconium phosphate $(1.47,1.02 \mathrm{~nm}$, respectively). Therefore, this material is expected to be a suitable host for intercalation of huge basic guests.
\end{abstract}

Keywords. $\quad \lambda$-Zirconium phosphate; adipate; topotactic anion exchange; organic-inorganic materials.

\section{Introduction}

The art or science of designing and synthesizing organic molecules has reached very high levels of sophistication, based on a relatively simple set of rules that guide both the invention and synthesis of new compounds. This set of rules is construed as the rational synthetic method of organic chemistry. As material chemists confronted to the task of building new solid structures with tailored chemical properties, we do inevitably need to develop some rational approach and to establish the corresponding set of rules allowing a realistic level of predictive knowledge in the construction of solid scaffolds. These conditions are reasonably accomplished by the use of layered salts of tetravalent transition metals, namely zirconium phosphate.

There are two main phases of zirconium phosphate, named $\alpha$ - and $\gamma$-ZrP, which vary in their interlaminar spaces and their crystalline structures. In both $\alpha$ and $\gamma$ structures (figure 1) zirconium coordinates octahedrally to six oxygens of six surrounding phosphates. However, in the former there is a single type of phosphate $\left(\mathrm{HPO}_{4}\right)$, whereas in the $\gamma$-phase there are two

\footnotetext{
*For correspondence
}

types of phosphates: internal $\mathrm{PO}_{4}$ groups and superficial $\mathrm{H}_{2} \mathrm{PO}_{4}$ groups. Thus, the chemical formulae for $\alpha$ and $\gamma-\mathrm{ZrP}$ are $\mathrm{Zr}\left(\mathrm{HPO}_{4}\right)_{2} \cdot \mathrm{H}_{2} \mathrm{O}$ and $\mathrm{Zr}\left(\mathrm{PO}_{4}\right)\left(\mathrm{H}_{2} \mathrm{PO}_{4}\right)$. $2 \mathrm{H}_{2} \mathrm{O}$, respectively. ${ }^{1,2}$

A third type related to $\gamma$ - $\mathrm{ZrP}$ (figure 2) can be formed by bridging four different zirconium atoms with $\left(\mathrm{PO}_{4}\right)$ in a similar manner to that of $\gamma-\mathrm{ZrP}$ then balancing the residual positive charge and completing the octahedral configuration of each zirconium atom with a monovalent anionic monodentate ligand (flouride or chloride) and neutral monodentate ligand (dimethyl sulphoxides). ${ }^{3,4}$ The building blocks of this lamellar structure are shown in figure 2.

The topotactic exchange of chloride ligand of $\lambda$ - $\mathrm{ZrP}$ $\left[\lambda-\mathrm{ZrPO}_{4} \mathrm{Cl}\left(\mathrm{CH}_{3}\right)_{2} \mathrm{SO}\right]$ with monoalkoxides and monocarboxylate ligands was reported for the first time by Vivani et al. in $2004 .^{5}$

There are very few examples in the literature about the construction of supramolecular assemblies at the solid state, in which $\lambda$-ZrP is used as template. ${ }^{6}$ In this regard, the construction of organic-inorganic layered materials based on $\lambda-\mathrm{ZrP}$ with tailor-made functionalities is a very young and promising technique.

This paper especially focuses on the synthesis and characterization of a new acidic layered material based on $\lambda$ - $\mathrm{ZrP}$ and adipate monovalent anion (figure 3 ). 

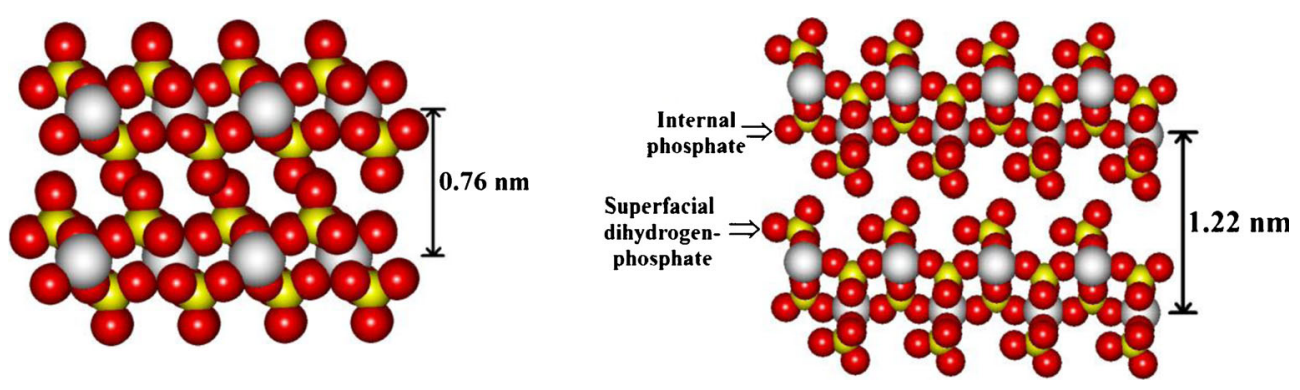

Figure 1. Space-filling models ( $\mathrm{Zr}$, gray; $\mathrm{P}$, yellow; $\mathrm{O}$, red; $\mathrm{H}$, has been omitted for sake of clarity) of two consecutive layers of $\alpha-\mathrm{ZrP}$ (left) and $\gamma$-ZrP (right). The experimental interlayer distances are shown.

\section{Experimental}

All chemicals and reagents used were of analytical grade. All of them were purchased from Aldrich Co. and used as supplied. $\lambda$-Zirconium phosphates was prepared using a procedure described in literature procedure described in literature (interlayer distance $1.02 \mathrm{~nm})^{7}$

\subsection{Topotactic exchange of adipate with $\lambda-\mathrm{ZrP}$}

A $0.25 \mathrm{~g}$ of $\mathrm{ZrPO}_{4} \mathrm{Cl}(\mathrm{dmso})$ was suspended in $17 \mathrm{~mL}$ of a $0.025 \mathrm{M}$ adipic acid and $0.025 \mathrm{M}$ sodium adipate solution using a $1: 1 \mathrm{v} / \mathrm{v}$ dmso/water mixture as solvent. The mixture was heated at $75^{\circ} \mathrm{C}$ for 3 days. The resulting white solid was separated by centrifugation and washed with a $1: 1 \mathrm{v} / \mathrm{v}$ dmso/water mixture $(2 \times 25 \mathrm{~mL})$. Finally, it was dried at $80^{\circ} \mathrm{C}$ for $24 \mathrm{~h}$ to obtain $0.27 \mathrm{~g}$ of the product which was stored over $\mathrm{P}_{2} \mathrm{O}_{5}$.

Anal. Calcd (found) for $\mathrm{ZrPO}_{4}\left(\mathrm{C}_{6} \mathrm{H}_{9} \mathrm{O}_{4}\right)\left(\mathrm{CH}_{3}\right)_{2} \mathrm{SO}$ : $\% \mathrm{C}, 23.52$ (23.48); \%H, 3.45 (3.40); \% S, 7.85 (7.91).

\subsection{Characterization}

X-ray powder diffraction (XRD) patterns were recorded at room temperature on Siemens D-5000 diffractometers with $\mathrm{Cu} \mathrm{K} \alpha$ radiation $(\lambda=0.154 \mathrm{~nm})$ and $\mathrm{Ni}$ filter at $40 \mathrm{kV}, 30 \mathrm{~mA}$, a scanning rate of $5^{\circ} / \mathrm{min}^{-1}$, and a $2 \theta$ angle ranging from $3^{\circ}$ to $70^{\circ}$. Infrared spectra were recorded on a FTIR-8201PC spectrometer using $\mathrm{KBr}$ disk in the range of 4000 to $400 \mathrm{~cm}^{-1}$. Elemental analyses were performed on a Perkin Elmer II $2400 \mathrm{CHN}$ analyzer. Thermogravimetric analyses were performed on a Mettler-Toledo TGA/STDA 851e apparatus and recorded at $5^{\circ} \mathrm{C} / \mathrm{min}$. Structure modelling was carried out on PC computers using the Hyperchem release 7 and the molecular mechanics method MM+.

\section{Results and discussion}

The adipate/ $\mathrm{Cl}$ exchange reaction between $\lambda$-ZrP and adipate monovalent anions occurs on the surface of the inorganic layers. Therefore, this reaction is expected to take place in a topotactic manner, i.e., it occurs

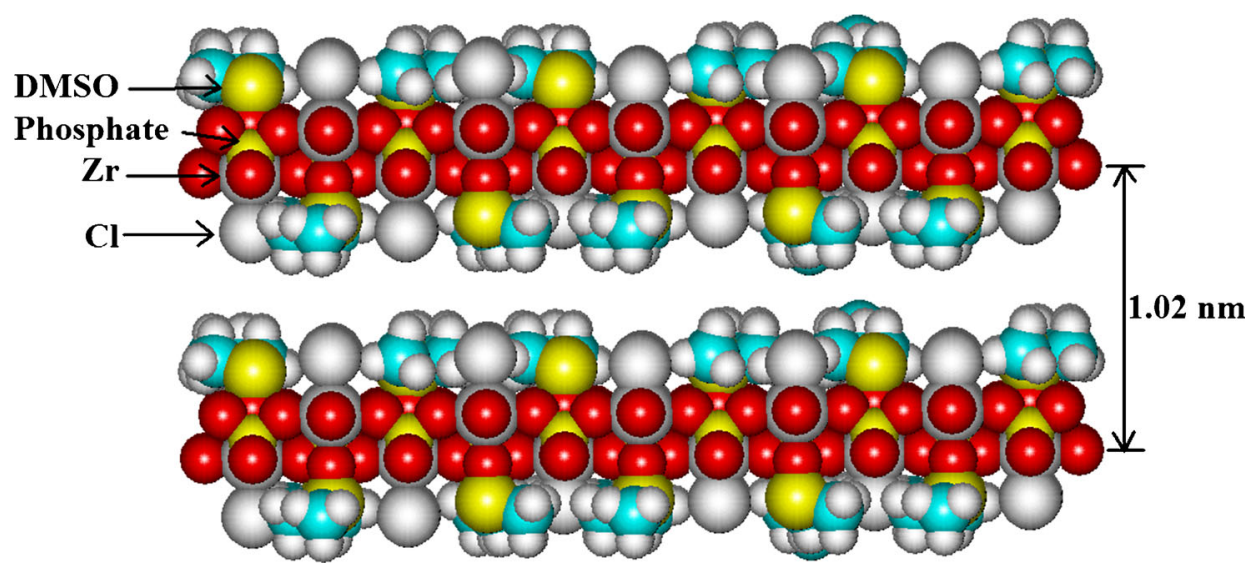

Figure 2. Space-filling model of $\lambda-\mathrm{ZrP}$. The experimentally measured interlayer distance is shown. 


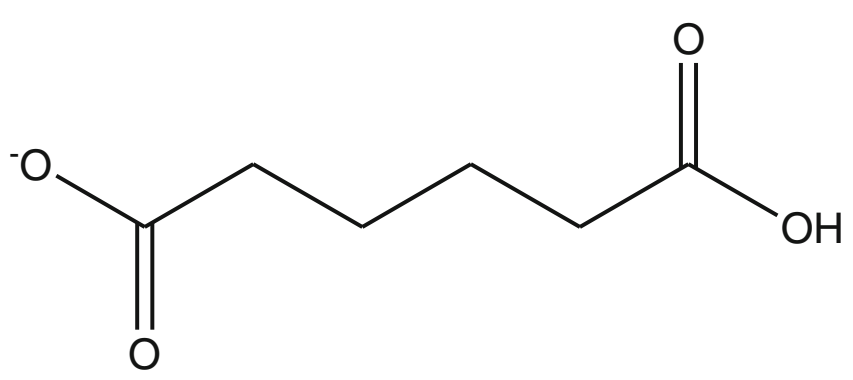

Figure 3. Structure of adipate mono anion.

without affecting the integrity and rigidity of the inorganic layers.

In practice, $\lambda$-ZrP is brought into contact with adipic acid/adipate (AA) equimolar mixture using a 1:1 v/v dmso/water mixture as solvent. This reaction led to a material designated as $\lambda$-ZrP-AA with a formula $\quad\left[\lambda-\mathrm{ZrPO}_{4}\left(\mathrm{OOC}-\left(\mathrm{CH}_{2}\right)_{4}-\mathrm{COOH}\right)\left(\mathrm{CH}_{3}\right)_{2} \mathrm{SO}\right]$ compatible with elemental analysis (see section 2 ).

As an important point to be mentioned, the absence of chloride in the chemical formula of $\lambda$-ZrP-AA emphasizes the complete replacement of the chloride anions of $\lambda-Z \mathrm{rP}$ by those of adipate.

The chemical formula of $\lambda$-ZrP-AA is confirmed by thermogravimetric analysis (TGA; figure 4). The TGA curve shows two well-defined weight loss intervals. The first one $\left(200-375^{\circ} \mathrm{C}\right)$ corresponds to the loss of dmso. The second weight loss interval $\left(375-600^{\circ} \mathrm{C}\right)$ caused by decomposition of the adipate moiety. The total weight loss at $1000^{\circ} \mathrm{C}$ $(51.24 \%)$ is in good agreement with the calculated one $(52.50 \%)$. The later percentage is calculated according to the following proposed thermal decomposition process.

$$
\begin{aligned}
& \lambda-\mathrm{ZrPO}_{4}\left(\mathrm{OOC}-\left(\mathrm{CH}_{2}\right)_{4}-\mathrm{COOH}\right)\left(\mathrm{CH}_{3}\right)_{2} \mathrm{SO} \rightarrow \lambda-\mathrm{ZrPO}_{4}\left(\mathrm{OOC}-\left(\mathrm{CH}_{2}\right)_{4}-\mathrm{COOH}\right) \\
& \quad+\text { gaseous products } \rightarrow 1 / 2 \mathrm{ZrO}_{2}+1 / 2 \mathrm{ZrP}_{2} \mathrm{O}_{7}+\text { gaseous products }
\end{aligned}
$$

The XRD pattern of $\lambda$-ZrP-AA (figure 5) allows the calculation of an interlayer distance of about $1.47 \mathrm{~nm}$, much larger than that of the pristine $\lambda-\mathrm{ZrP}(1.02 \mathrm{~nm}$; figure 5). Moreover, the compound seems to contain a small amount of an extra phase, due to the presence of a peak around $1.0 \mathrm{~nm}$ in the X-ray powder diffraction pattern. This cannot be a residue of the pristine $\mathrm{ZrPCl}(\mathrm{dmso})$, because the composition data did not reveal chloride. However, this extra peak can be attributed to a small amount of the $\mathrm{ZrPO}_{4} \mathrm{OHdmso}$ phase, in which $\mathrm{Cl}$ is replaced by $\mathrm{OH}$ anions, as

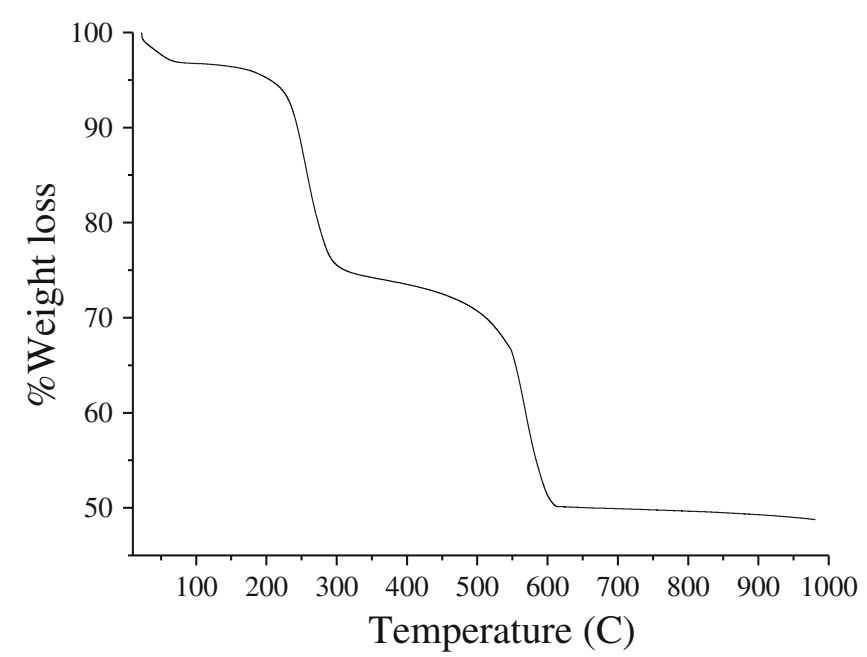

Figure 4. TGA curve of $\lambda-\mathrm{ZrP}-\mathrm{AA}$ obtained at a heating rate $5^{\circ} \mathrm{C} / \mathrm{min}$. desribed in case of other similar $\lambda$-type derivatives. ${ }^{6,7}$ The $\mathrm{OH}$ exchanged phase has an interlayer distance of $0.98 \mathrm{~nm}$, slightly smaller than the pristine $\mathrm{Cl}$ phase, in agreement with the reported XRD pattern. Due to the presence of preferred orientation effects in the XRD pattern, that usually occur in this kind of materials, even though the $\mathrm{OH}$-phase peak is relatively high, the phase amount may be small and not sensibly affect the reported analytical data.

Figure 6 shows the structure of the most stable conformer of $\mathrm{AA}$ as calculated by $\mathrm{MM}+$ molecular

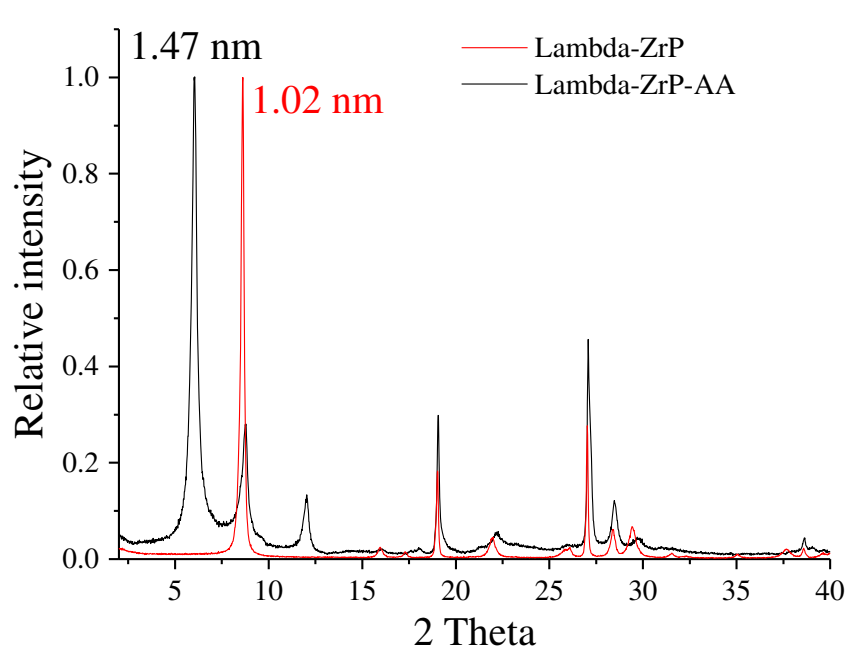

Figure 5. $\mathrm{X}$-ray powder diffraction patterns of $\lambda-\mathrm{ZrP}$ and $\lambda$-ZrP-AA. 


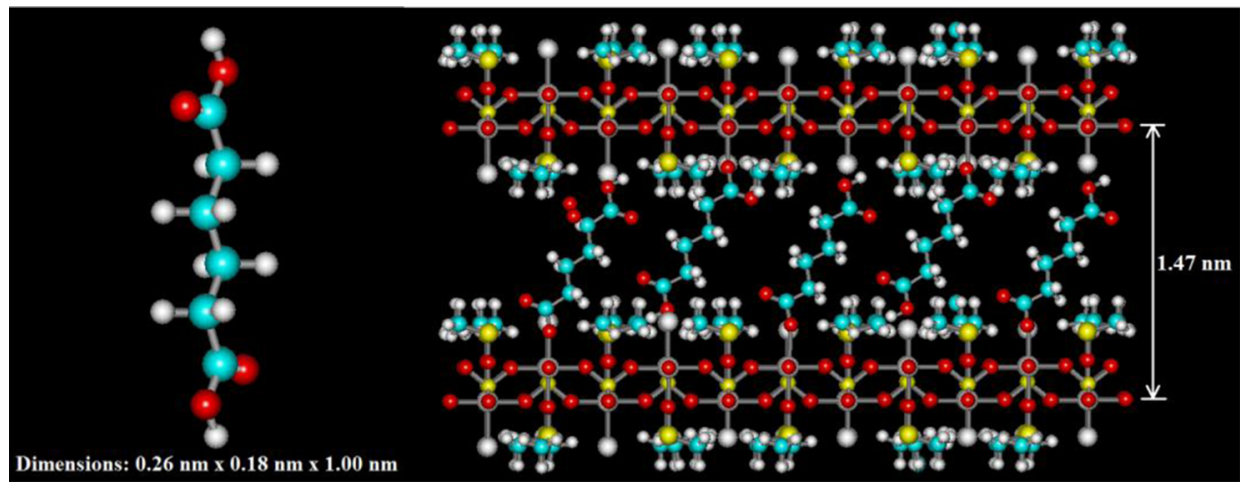

Figure 6. Calculated structures: Predicted most stable conformation of AA (HyperChem, MM+) (left). Possible arrangement of AA molecules in $\lambda$-ZrP complying with the observed interlayer distance of $\lambda$-ZrP-AA (right).

mechanics method. Also, figure 6 shows a plausible arrangement of AA molecules within $\lambda-\mathrm{ZrP}$ complying with the measured interlayer distance of $\lambda$-ZrP-AA. It can be seen that the adipate chains are in a completely extended conformation (zigzag shape) and they arrange themselves inside the interlayer gallery of $\lambda-\mathrm{ZrP}$ as monomolecular layer.

The FT-IR spectrum of the pristine $\lambda$-ZrP (figure 7) shows its typical characteristic peaks. ${ }^{6}$ The bands at low-frequency region are ascribed to $\mathrm{PO}_{4}$ vibration bands. The bands around $3000 \mathrm{~cm}^{-1}$ are assigned to $\mathrm{C}-\mathrm{H}$ symmetric and asymmetric stretching vibrations of dmso methyl groups and those at 1420 and $1320 \mathrm{~cm}^{-1}$ are attributed to symmetric and asymmetric bending vibrations of the same groups.

In case of $\lambda$-ZrP-AA, the FT-IR spectrum is mostly composite of those of $\lambda-\mathrm{ZrP}$ and free AA (figure 7). The band at $1692 \mathrm{~cm}^{-1}(\mathrm{COOH})$ in FT-IR spectrum of adipic acid (AA) is red shifted to be at lower frequencies $\left(1657 \mathrm{~cm}^{-1}\right)$ in that of $\lambda$-ZrP-AA.
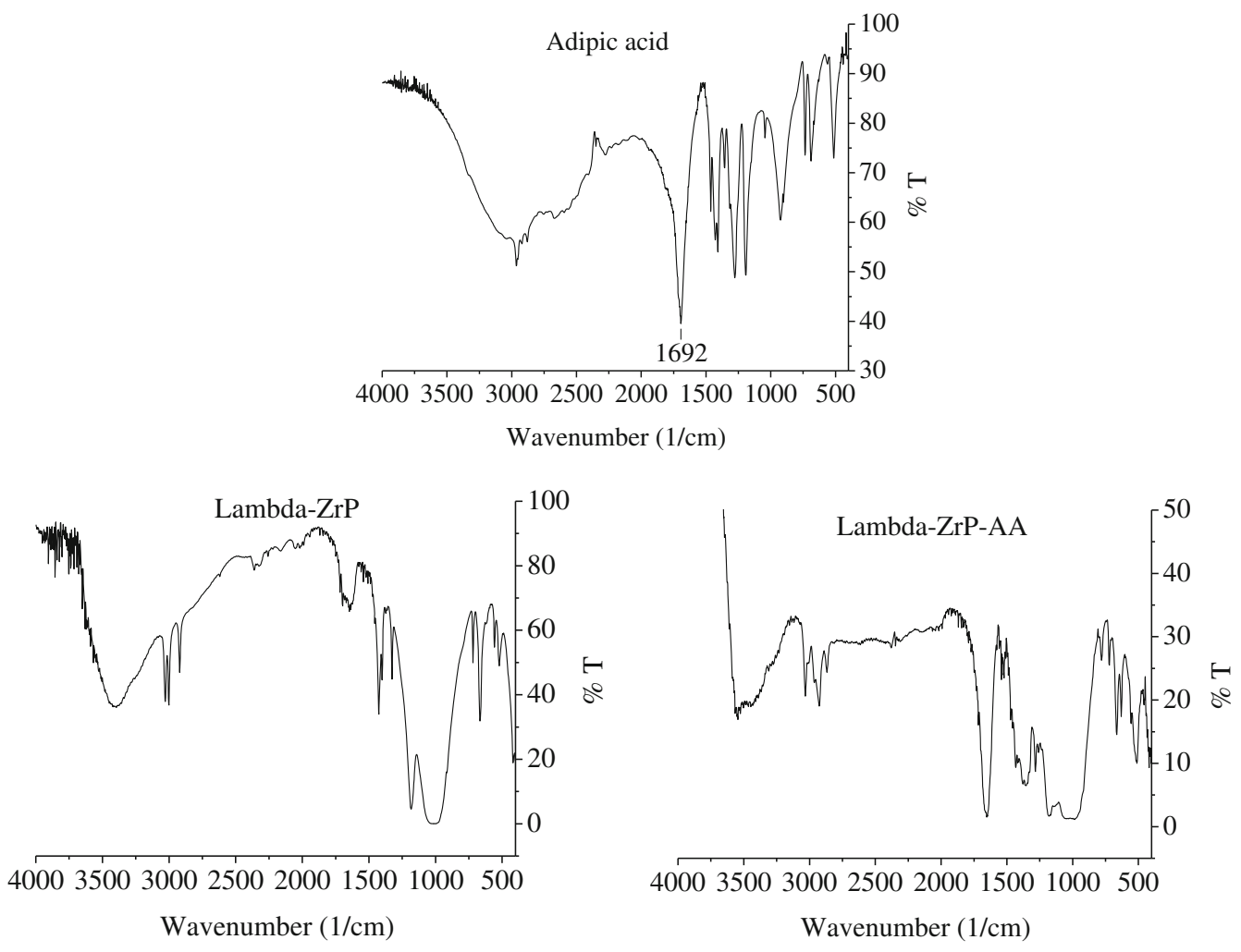

Figure 7. FT-IR spectra of the free adipic acid (AA), $\lambda-\mathrm{ZrP}$ and $\lambda-\mathrm{ZrP}-\mathrm{AA}$. 


\subsection{Related work}

Some aromatic monocarboxylate derivatives of general formula $\mathrm{ZrPO}_{4}\left[(\mathrm{RCOO})\left(\mathrm{CH}_{3}\right)_{2} \mathrm{SO}\right]_{1-\mathrm{x}}\left(\mathrm{OH} \mathrm{H} \mathrm{H}_{2} \mathrm{O}\right)_{x}$, where $\mathrm{R}=$ benzoate, nitrobenzoate or phenylacetate, were prepared for the first time by Vivani et al. in 2004. ${ }^{5}$ To the best of our knowledge, the aliphatic mono- and dicarboxlylate derivatives of $\lambda-\mathrm{ZrP}$ have not yet been described in the literature.

This research study aims to obtain a layered $\lambda$-phase aliphatic dicarboxylic derivative $\left[\lambda-\mathrm{ZrPO}_{4}(\mathrm{OOC}\right.$ $\left.\left.\left(\mathrm{CH}_{2}\right)_{4}-\mathrm{COOH}\right)\left(\mathrm{CH}_{3}\right)_{2} \mathrm{SO}\right]$ through topotactic exchange reaction between the superficial chloride ligands of the inorganic layer of the pristine $\lambda-\mathrm{ZrP}$ and the monoanionic adipate ligands.

It is well-known that intercalation chemistry of $\alpha$ and $\gamma-\mathrm{ZrP}$ (figure 1) is dominated by the presence in the interlayer region of Brønsted acid groups. ${ }^{8}$ The presence of the free $-\mathrm{COOH}$ groups at the ends of the aliphatic chains of the adipate moieties inside the solid matrix (figure 6) imparts Brønsted acidic character to the pristine $\lambda-\mathrm{ZrP}$ (figure 2). Therefore, our new HOOC-functionalized host ( $\lambda$-ZrP-AA) could be of great importance for intercalation of huge basic guests. $^{9-11}$

\section{Conclusion}

Elemental and thermogravimetric analyses, X-ray diffractometry, FT-IR spectroscopy and molecular modelling indicate that the adipate monovalent anion is successfully exchanged with $\lambda$-ZrP by means of topotactic adipate/ $\mathrm{Cl}$ ligand exchange reaction. Therefore, a new acidic $\lambda$-type layered material $\left[\lambda-\mathrm{ZrPO}_{4}\left(\mathrm{OOC}-\left(\mathrm{CH}_{2}\right)_{4}\right.\right.$ $\left.\mathrm{COOH})\left(\mathrm{CH}_{3}\right)_{2} \mathrm{SO}\right]$ has been prepared.

\section{Acknowledgement}

The author is thankful to the Association of Arab Universities for financial support. The author also thanks Prof. Ernesto Brunet and Elena Rodríquez Payán and María de Victoria Rodríquez two PhD students of Universidad Autónoma de Madrid for performing some important experiments to characterize the samples.

\section{References}

1. Alberti G 1998 Sci. Tech. 80607

2. Alberti G, Casciola M, Costantino U and Vivani R 1996 Adv. Mater. 8291

3. Poojary D M, Zhang B and Clearfield A 1994 J. Chem. Soc. Dalton Trans 162453

4. Alberti G, Bartocci M, Santarelli M and Vivani R 1997 Inorg. Chem. 363574

5. Vivani R, Masci S and Alberti G 2004 Inorg. Chem. $\mathbf{4 3}$ 368

6. Caneschi A, Gatteschi D, Sangregorio C, Vaz M G F, Costantino U, Nocchetti M and Vivani R 2002 Iorg. Chem. Acta. 338127

7. Alberti G, Masci S and Vivani R 2002 Inorg. Chem. 41 1913

8. Clearfield A and Costantino U 1996 In Comprehensive Supramolecular Chemistry, Alberti G and Bein T (ed.) (New York: Pergamon) vol. 7, Chap. 4

9. Alhendawi H, Brunet E, Rodríguez Payán E, Juanes O, Rodríguez Ubis J C and Al-Asqalany M $2012 \mathrm{~J}$. Incl. Phenom. Macrocycl. Chem. $\mathbf{7 3} 387$

10. Alhendawi H 2011 J. Mater. Chem. 217748

11. Hoppe R, Alberti G, Costantino U, Dionigi C, SchulzEkloff G and Vivani R 1997 Langmuir 137252 